\title{
Associations Among Plasma Stress Markers and Symptoms of Anxiety and Depression in Patients with Breast Cancer Following Surgery
}

\author{
Hyun-Bin Ju', Eun-Chan Kang ${ }^{1}$, Dong-Wook Jeon ${ }^{1}$, Tae-Hyun Kim², \\ Jung-Joon Moon ${ }^{1}$, Sung-Jin Kim¹, Ji-Min $\mathrm{Choi}^{3}$, and Do-Un Jung ${ }^{1 凶}$ \\ ${ }^{1}$ Department of Psychiatry, Busan Paik Hospital, Inje University College of Medicine, Busan, Republic of Korea \\ ${ }^{2}$ Department of Surgery, Busan Paik Hospital, Inje University College of Medicine, Busan, Republic of Korea \\ ${ }^{3}$ Department of Information Management Systems, Dong-A University, Busan, Republic of Korea
}

Objective The objective of present study is to analyze the prevalence of depression and anxiety following breast cancer surgery and to assess the factors that affect postoperative psychological symptoms.

Methods The Hamilton Rating Scale for Depression (HAM-D), Hamilton Anxiety Rating Scale (HAM-A), Body Image Scale (BIS), and Rosenberg Self Esteem Scale (RSES) were used to assess the psychological states of patients who had been diagnosed with and had undergone surgery for breast cancer. Blood concentrations of the stress markers adrenocorticotropic hormone, cortisol, arginine-vasopressin, and angiotensin-converting enzyme were measured. Pearson's correlation analysis and multilinear regression analysis were used to analyse the data.

Results At least mild depressive symptoms were noted in $50.5 \%$ of patients, while $42.4 \%$ of patients exhibited at least mild anxiety symptoms. HAM-D score was positively correlated with HAM-A $(r=0.83, p<0.001)$ and BIS $(r=0.29, p<0.001)$ scores and negatively correlated with RSES score $(\mathrm{r}=-0.41, \mathrm{p}<0.001)$. HAM-A score was positively correlated with BIS score $(\mathrm{r}=0.32, \mathrm{p}<0.001)$ and negatively correlated with RSES score $(r=-0.27, p<0.001)$. There were no statistically significant associations between stress markers and depression/anxiety.

Conclusion Patients with breast cancer frequently exhibit postoperative depression and anxiety, which are related to low levels of self-esteem and distorted body image.

Psychiatry Investig 2018;15(2):133-140

Key Words Breast cancer, Body image, HPA axis, Depression, Anxiety.

\section{INTRODUCTION}

Breast cancer, which has one of the highest rates of prevalence and survival among tumor-related conditions, is one of the most vigorously studied diseases in the field of psychooncology. ${ }^{1}$ The incidence rate of in situ breast cancer in women age 50 or under increased by $1.9 \%$ annually between 1998 and 2010, while breast cancer death rates decreased by $34 \%$ between 1990 and 2010 in the United States. ${ }^{2}$ One of the reasons for such a trend is that advances in screening methods

Received: May 10, 2017 Accepted: July 26, 2017

Available online: October 30, 2017

$\triangle$ Correspondence: Do-Un Jung, MD, PhD

Department of Psychiatry, Busan Paik Hospital, Inje University College of Medicine, 75 Bokji-ro, Busanjin-gu, Busan 47392, Republic of Korea Tel: +82-51-890-6189, Fax: +82-51-894-2532, E-mail: gabriel.jdu@gmail.com

(a) This is an Open Access article distributed under the terms of the Creative Commons Attribution Non-Commercial License (http://creativecommons.org/licenses/bync/4.0) which permits unrestricted non-commercial use, distribution, and reproduction in any medium, provided the original work is properly cited. and oncological treatment have enabled both early detection and increased survival rates. ${ }^{3}$

Increased long-term survival rates have directed the attention of researchers and clinicians toward quality of life for patients with breast cancer, who often undergo various complementary therapies, such as radiotherapy, chemotherapy, and hormone therapy in addition to surgery. Such intensive treatment often results in increased psychological symptoms such as postoperative depression, anxiety, distorted body image, and reduced self-esteem. In particular, symptoms of depression and anxiety in patients with breast cancer not only impact overall quality of life by reducing social function and social adaptation but also influence the progression and prognosis of cancer itself. ${ }^{4,5}$ In this context, the need for active management of mental health issues in patients with breast cancer undergoing intensive treatment is of paramount importance. ${ }^{4}$

Compared to the general population, patients with breast cancer patients exhibit a higher prevalence of depressive symp- 
toms and major depressive disorder in the early period following surgery. ${ }^{6}$ Research also indicates that patients with breast cancer are at high risk for depression within the first year of diagnosis, ${ }^{7}$ and that around $20-30 \%$ of all patients with breast cancer develop psychiatric conditions such as anxiety and depression within the first year after surgery. ${ }^{8,9}$ Furthermore, approximately one-third of patients who undergo surgical treatment for breast cancer experience depression and anxiety within three months after surgery. ${ }^{10}$ Therefore, screening for patients at high risk for psychological pain in the early stages of breast cancer is critical in order to provide immediate and appropriate intervention, which has been associated with improved quality of life and increased long-term survival rates. ${ }^{7}$

Women who have been treated for breast cancer undergo marked changes in physical appearance, primarily in terms of breast deformity, surgical scarring, and skin degeneration due to radiotherapy. ${ }^{11}$ Fingeret et al. ${ }^{12}$ suggested that various disease and treatment factors that are related to breast cancer (e.g., tumor features, genetic risk, type of surgery, type of reconstruction, time, stage, complications) influence the outcome of body image, which are predicted to be highly associated with psychological pain in patients with breast cancer.

Due to the aforementioned factors, patients experience psychological and physical stress during the process of breast cancer diagnosis and surgery. In such high-stress situations, hyperactivity of the hypothalamic-pituitary-adrenal (HPA) axis is known to be associated with the onset of depressive symptoms. ${ }^{13}$ In a psychologically stressful situation, the limbic system, including the hippocampus and amygdala, is activated, and secretion of corticotropin-releasing hormone (CRH) and arginine-vasopressin (AVP) is increased in the hypothalamus. $\mathrm{CRH}$ acts on the pituitary gland to induce the secretion of adrenocorticotropic hormone (ACTH), which in turn acts on the adrenal gland to stimulate the production and release of cortisol. ${ }^{13-15}$ AVP itself plays a minimal role in stimulating ACTH secretion, but in a synergistic action with $\mathrm{CRH}$, AVP increases ACTH secretion in the pituitary. ${ }^{16}$ Apart from CRH, single nucleotide polymorphisms (SNP) of angiotensin-converting enzyme and vasopressin $\mathrm{V} 1 \mathrm{~B}$ receptors are known to influence reactions to dexamethasone/CRH testing as well as vulnerability to stress-related depression. ${ }^{17}$

As studies have revealed that various stress factors, such as cancer diagnosis and surgery, contribute to hyperactivity of the HPA axis and that resulting changes in inflammation and immune functions are associated with depression, the importance of stress markers as predictors of depression and anxiety has been highlighted. ${ }^{14,15}$ Furthermore, research has revealed that treatment of depressive symptoms and subsequent relief of psychological pain normalize the function of the HPA axis. ${ }^{18}$

The objective of the present study is to assess the preva- lence of depression and anxiety following breast cancer surgery and to verify the association between blood stress markers (e.g., cortisol) and psychological symptoms.

\section{METHODS}

\section{Patients}

This study was conducted with female patients who had been diagnosed with and had received surgery for breast cancer at the Breast Center at Busan Paik Hospital. All patients had been referred for psychiatric evaluation between May 2014 and April 2016. Patients who underwent surgery in a small area (i.e., breast needle biopsy and mass excision) were excluded. Information such as history, presence of accompanying illness, and type and range of breast cancer surgery were identified through medical records, and information was verified via patient interviews when medical records contained insufficient data. Informed consent was obtained from all individual participants included in the study. This study was approved by the Institutional Review Board of Busan Paik Hospital, Inje University, Busan, Korea (IRB No. 16-057).

\section{Psychological assessment}

\section{Hamilton Rating Scale for Depression (HAM-D)}

The HAM-D is the most widely utilized tool for the evaluation of depressive symptoms. ${ }^{19}$ Developed in 1960, the HAM$\mathrm{D}$ is a 17-item clinician-administered assessment scale that is especially sensitive to changes experienced by patients with severe depression, as it emphasizes the physical symptoms of depression. Scores range from 0 to 50 points, with higher scores indicating more severe depressive symptoms. Riedel et al. ${ }^{20}$ considered a score between $0-6$ indicative of no depression, 7-17 indicative of mild depression, 18-24 indicative of moderate depression, and greater than 24 indicative of severe depression.

\section{Hamilton Anxiety Rating Scale (HAM-A)}

The HAM-A is a 14-item scale that assesses the severity of anxiety symptoms. ${ }^{21}$ Developed by Hamilton in 1959, the HAM-A involves a semi-structured interview during which the interviewer directly evaluates the patient. The symptoms are broadly categorized into general mental anxiety symptoms, cognitive symptoms, and physical symptoms, which are further subdivided into 14 categories. Scores range from 0-56 points, with higher scores indicating more severe anxiety symptoms. A score between 8-14 indicates mild anxiety, 1523 indicates moderate anxiety, and greater than 24 indicates severe anxiety. ${ }^{22}$ 


\section{Body Image Scale (BIS)}

The BIS is a 10-item self-report questionnaire that was developed by Hopwood in 2001 to evaluate body image in patients with cancer. ${ }^{23}$ Five items relate to types of happiness/satisfaction associated with body image, while the remaining five relate to experiences associated with cancer. Patients with more severely distorted body image present with higher scores, with total scores ranging from $0-30$ points.

\section{Rosenberg Self Esteem Scale (RSES)}

Developed by Rosenberg, ${ }^{24}$ the RSES measures the degree of an individual's self-esteem and self-approval patterns. It includes a total of 10 items, five of which are related to positive self-esteem, while the remaining five are related to negative self-esteem. Scores range from 10-40 points, with higher scores indicating higher levels of self-esteem.

\section{Stress markers}

We measured the concentrations of ACTH, cortisol, AVP, and ACE from blood samples obtained from each patient the morning prior to surgery. This is considered an appropriate time to obtain blood samples for control, as anesthetics, surgi$\mathrm{cal}$ and anesthetic techniques, and postoperative prognosis may act as confounding factors following surgery.

\section{Statistical analysis}

Variables were summarized by frequency and percentage for categorical data and mean \pm standard deviation for numeric data. Group differences were analyzed using the chi-squared test for categorical data and independent $t$-test for numeric data. The Pearson's correlation coefficients were estimated in order to investigate the association between predictors and HAM-D/HAM-A scores. The effect of independent variables on HAM-D/HAM-A scores was analyzed using multivariate linear regression. All statistical analyses were performed using SPSS Version 23.0 (IBM Corp., Armonk, NY, USA), and p values less than 0.05 were considered statistically significant.

\section{RESULTS}

\section{Characteristics of breast cancer patients}

A total of 198 female patients (mean age: $53.1 \pm 10.3$ years; range: $27-78$ ) were enrolled. The time from the end of surgery to the psychiatric interview ranged from 1-17 days; on average, patients underwent assessment on postoperative day 4.4. The sociodemographic/clinical characteristics of the included patients are summarized in Table 1.

\section{Factors associated with symptoms of depression and anxiety in patients with breast cancer}

A total of 100 patients (50.5\%) were classified with mild or more severe depression (HAM- $\mathrm{D} \geq 7$ ), while 21 patients $(10.6 \%)$ were classified with moderate or more severe depression (HAM-D $\geq 18$ ). A total of 84 patients (42.4\%) were classified with mild or more severe anxiety (HAM-A $\geq 8$ ),

Table 1. Demographic and clinical data of patients with breast cancer

\begin{tabular}{|c|c|}
\hline Variable & $\mathrm{N}(\%) /$ mean $\pm \mathrm{SD}$ \\
\hline All patients & $198(100.0)$ \\
\hline Age (years) & $53.1 \pm 10.3(27-78)$ \\
\hline Diabetes mellitus & $21(10.6)$ \\
\hline Hypertension & $38(19.2)$ \\
\hline Past psychiatric history & $7(3.5)$ \\
\hline BMI & $24.1 \pm 3.6(17.7-36.3)$ \\
\hline Menopause & $108(54.5)$ \\
\hline Breast cancer family history & $11(5.6)$ \\
\hline Breast cancer recurrence & $16(8.1)$ \\
\hline Prior breast cancer surgery & $26(13.1)$ \\
\hline Prior chemotherapy & $32(16.2)$ \\
\hline Prior radiation therapy & $8(4.0)$ \\
\hline Prior hormone therapy & $1(0.5)$ \\
\hline Prior target therapy & $9(4.5)$ \\
\hline \multicolumn{2}{|l|}{ Cancer classification } \\
\hline \multicolumn{2}{|l|}{ Pathologic type } \\
\hline DCIS & $60(30.3)$ \\
\hline IDC & $123(62.1)$ \\
\hline Others & $15(7.6)$ \\
\hline \multicolumn{2}{|l|}{ Cancer staging } \\
\hline IA, IB: 1 & $40(20.2)$ \\
\hline IIA, IIB: 2 & $35(17.7)$ \\
\hline IIIA, IIIB, IIIC: 3 & $23(11.6)$ \\
\hline IV: 4 & $4(2.0)$ \\
\hline \multicolumn{2}{|l|}{ Molecular subtype } \\
\hline Luminal type A & $39(19.7)$ \\
\hline Luminal type B & $98(49.5)$ \\
\hline HER 2 positive type & $18(9.1)$ \\
\hline Basal-like type & $34(17.2)$ \\
\hline \multicolumn{2}{|l|}{ Surgery type } \\
\hline Simple mastectomy & $3(1.5)$ \\
\hline BCS & $122(61.6)$ \\
\hline SSM & $52(26.3)$ \\
\hline MRM & $21(10.6)$ \\
\hline Axillary lymph node dissection & $51(25.8)$ \\
\hline Body surface area & $1.60 \pm 0.13(1.37-2.21)$ \\
\hline
\end{tabular}

Values are mean \pm SD (min-max) for continuous variables. BCS: breast conserving surgery, BMI: body mass index, DCIS: ductal carcinoma in situ, HER: human epidermal growth factor receptor, IDC: invasive ductal carcinoma, MRM: modified radical mastectomy, SSM: skin sparing mastectomy 
while 31 patients $(15.6 \%)$ were classified with moderate or more severe anxiety (HAM-A $\geq 15$ ).

Patients were dichotomized according to HAM-D score (low HAM-D/high HAM-D) using a cut-off of 7. However, no significant association was observed between any demographic or clinical variable and HAM-D score. Patients were dichotomized according to HAM-A score (low HAM-A/high HAM-A) using a cut-off of 8 . A significant association between past psychiatric history and HAM-A score was observed. In the low HAM-A group (scores $<8$ ), one patient $(0.9 \%)$ exhibited past psychiatric history, compared with six patients (7.1\%) in the high HAM-A group (scores $\geq 8$ ) (chi-square $\mathrm{p}$ value= 0.018). HAM-A score was not associated with recurrence of breast cancer, treatment history, or surgical method (Table 2).

\section{Association between psychological scores and blood stress markers}

The correlations between HAM-D/HAM-A scores and

Table 2. Association between HAM-D/HAM-A scores and demographic/clinical data of patients with breast cancer

\begin{tabular}{|c|c|c|c|c|c|c|}
\hline \multirow[b]{2}{*}{ Variable } & \multicolumn{2}{|c|}{ HAM-D } & \multirow[b]{2}{*}{$\mathrm{p}$ value } & \multicolumn{2}{|c|}{ HAM-A } & \multirow[b]{2}{*}{$\mathrm{p}$ value } \\
\hline & $\begin{array}{l}\text { Healthy group } \\
<7(\mathrm{~N}=98)(\%)\end{array}$ & $\begin{array}{l}\text { Depression group } \\
\geq 7(\mathrm{~N}=100)(\%)\end{array}$ & & $\begin{array}{c}\text { Healthy group } \\
<8(\mathrm{~N}=114)(\%)\end{array}$ & $\begin{array}{l}\text { Anxiety group } \\
\geq 8(\mathrm{~N}=84)(\%)\end{array}$ & \\
\hline Age (years) & $52.8 \pm 9.1$ & $53.4 \pm 11.4$ & 0.677 & $53.3 \pm 9.5$ & $52.8 \pm 11.5$ & 0.709 \\
\hline Diabetes mellitus & $7(7.1)$ & $14(14.0)$ & 0.117 & $9(7.9)$ & $12(14.3)$ & 0.149 \\
\hline Hypertension & $19(19.4)$ & $19(19.0)$ & 0.945 & $24(21.1)$ & $14(16.7)$ & 0.439 \\
\hline Past psychiatric history & $1(1.0)$ & $6(6.0)$ & 0.058 & $1(0.9)$ & $6(7.1)$ & $0.018^{*}$ \\
\hline BMI & $24.5 \pm 3.6$ & $23.8 \pm 3.6$ & 0.175 & $24.3 \pm 3.5$ & $23.9 \pm 3.7$ & 0.368 \\
\hline Menopause & $56(57.1)$ & $52(52.0)$ & 0.467 & $67(58.8)$ & $41(48.8)$ & 0.164 \\
\hline Breast cancer family history & $6(6.1)$ & $5(5.0)$ & 0.730 & $5(4.4)$ & $6(7.1)$ & 0.403 \\
\hline Breast cancer recurrence & $11(11.2)$ & $5(5.0)$ & 0.108 & $12(10.5)$ & $4(4.8)$ & 0.141 \\
\hline Prior breast cancer surgery & $15(15.3)$ & $11(11.0)$ & 0.370 & $16(14.0)$ & $10(11.9)$ & 0.661 \\
\hline Prior chemotherapy & $15(15.3)$ & $17(17.0)$ & 0.746 & $22(19.3)$ & $10(11.9)$ & 0.162 \\
\hline Prior radiation therapy & $6(6.1)$ & $2(2.0)$ & 0.141 & $6(5.3)$ & $2(2.4)$ & 0.309 \\
\hline Prior hormone therapy & $1(1.0)$ & $0(0.0)$ & 0.311 & $1(0.9)$ & $0(0.0)$ & 0.389 \\
\hline Prior target therapy & $5(5.1)$ & $4(4.0)$ & 0.710 & $7(6.1)$ & $2(2.4)$ & 0.209 \\
\hline \multicolumn{7}{|l|}{ Cancer classification } \\
\hline Pathologic type & & & 0.698 & & & 0.972 \\
\hline DCIS & $29(29.6)$ & $31(31.0)$ & & $34(29.8)$ & $26(31.0)$ & \\
\hline IDC & $60(61.2)$ & $63(63.0)$ & & $71(62.3)$ & $52(61.9)$ & \\
\hline Others & $9(9.2)$ & $6(6.0)$ & & $9(7.9)$ & $6(7.1)$ & \\
\hline Cancer staging & & & 0.444 & & & $0.014^{*}$ \\
\hline IA, IB: 1 & $16(33.3)$ & $24(44.4)$ & & $15(26.8)$ & $25(54.3)$ & \\
\hline IIA, IIB: 2 & $18(37.5)$ & $17(31.5)$ & & $20(35.7)$ & $15(32.6)$ & \\
\hline IIIA, IIIB, IIIC: 3 & $13(27.1)$ & $10(18.5)$ & & $18(32.1)$ & $5(10.9)$ & \\
\hline IV: 4 & $1(2.1)$ & $3(5.6)$ & & $3(5.4)$ & $1(2.2)$ & \\
\hline Molecular subtype & & & 0.795 & & & 0.866 \\
\hline Luminal type A & $20(21.3)$ & $19(20.0)$ & & $25(22.7)$ & $14(17.7)$ & \\
\hline Luminal type B & $49(52.1)$ & $49(51.6)$ & & $56(50.9)$ & $42(53.2)$ & \\
\hline HER 2 positive type & $7(7.4)$ & $11(11.6)$ & & $10(9.1)$ & $8(10.1)$ & \\
\hline Basal-like type & $18(19.1)$ & $16(16.8)$ & & $19(17.3)$ & $15(19.0)$ & \\
\hline Surgery type & & & 0.382 & & & 0.796 \\
\hline Simple mastectomy & $0(0.0)$ & $3(3.0)$ & & $1(0.9)$ & $2(2.4)$ & \\
\hline BCS & $62(63.3)$ & $60(60.0)$ & & $69(60.5)$ & $53(63.1)$ & \\
\hline SSM & $26(26.5)$ & $26(26.0)$ & & $31(27.2)$ & $21(25.0)$ & \\
\hline MRM & $10(10.2)$ & $11(11.0)$ & & $13(11.4)$ & $8(9.5)$ & \\
\hline Axillary lymph node dissection & $25(25.5)$ & $26(26.0)$ & 0.937 & $33(28.9)$ & $18(21.4)$ & 0.232 \\
\hline Body surface area & $1.62 \pm 0.11$ & $1.59 \pm 0.14$ & 0.146 & $1.61 \pm 0.11$ & $1.60 \pm 0.15$ & 0.810 \\
\hline
\end{tabular}

${ }^{*} \mathrm{p}<0.05$. BCS: breast conserving surgery, BMI: body mass index, DCIS: ductal carcinoma in situ, HER: human epidermal growth factor receptor, IDC: invasive ductal carcinoma, MRM: modified radical mastectomy, SSM: skin sparing mastectomy 
other predictor variables are summarized in Table 3. HAM-D score was positively correlated with HAM-A ( $\mathrm{r}=0.83, \mathrm{p}<$ $0.001)$ and BIS $(r=0.29, p<0.001)$ score. Furthermore, HAMD score was negatively correlated with RSES score ( $r=-0.41$, $\mathrm{p}<0.001$ ), while HAM-A score was negatively correlated with RSES score $(\mathrm{r}=-0.27, \mathrm{p}<0.001)$ and positively correlated with BIS score $(r=0.32, p<0.001)$.

\section{Analysis of factors that affect symptoms of depression and anxiety}

Multivariate linear regression analyses revealed that RSES score was significantly associated with HAM-D score $(\beta=-0.368$, $\mathrm{p}<0.001)$, and that HAM-A score was significantly associated with BIS score $(\beta=0.251, p=0.003)$ (Table 4, Figures 1 and 2$)$.

\section{DISCUSSION}

In the present study, we revealed that depression was asso- ciated with high anxiety, low self-esteem, and highly distorted body image in patients with breast cancer. The psychological pain experienced by patients with breast cancer is influenced by individual psychological traits, including coping ability in response to stressful situations such as cancer. ${ }^{9}$ Psychologically, patients with cancer experience negative selfevaluation and suppression of/negative emotional responses related to low levels of self-esteem. Previous research has indicated that such psychological coping strategies are associated with depression following breast cancer surgery. ${ }^{1,10,14,25}$ Our results indicate that body image distortion is significantly associated with anxiety, aligning with those of previous studies, which have revealed that body image concerns are associated with depression and anxiety, and ultimately with low quality of life and difficulty in sex life, in patients with breast cancer. $^{26,27}$

In the present study, anxiety symptoms were significantly associated with psychiatric history but not with type or extent

Table 3. Correlation coefficients among depression, anxiety, self-esteem, body image, and serum stress markers

\begin{tabular}{|c|c|c|c|c|c|c|c|}
\hline & HAM-D & HAM-A & RESES & BIS & ACTH & AVP & $\mathrm{ACE}$ \\
\hline \multicolumn{8}{|l|}{ HAM-D } \\
\hline HAM-A & $0.83^{*}$ & & & & & & \\
\hline RSES & $-0.41^{*}$ & $-0.27^{*}$ & & & & & \\
\hline BIS & $0.29^{*}$ & $0.32^{*}$ & $-0.41^{*}$ & & & & \\
\hline ACTH & -0.01 & -0.02 & 0.07 & -0.05 & & & \\
\hline AVP & 0.02 & -0.01 & -0.05 & 0.04 & 0.06 & & \\
\hline $\mathrm{ACE}$ & 0.13 & 0.11 & -0.07 & 0.03 & -0.01 & -0.02 & \\
\hline Cortisol & -0.04 & -0.09 & 0.12 & -0.08 & $0.52^{*}$ & 0.03 & -0.11 \\
\hline
\end{tabular}

${ }^{*} \mathrm{p}<0.001$. HAM-D: Hamilton Rating Scale for Depression, HAM-A: Hamilton Anxiety Rating Scale, BIS: Body Image Scale, RSES: Rosenberg Self Esteem Scale, ACTH: adrenocorticotropic hormone, AVP: arginine-vasopressin, ACE: angiotensin-converting enzyme

Table 4. Variables predicting HAM-D and HAM-A scores

\begin{tabular}{|c|c|c|c|c|c|c|c|c|c|}
\hline \multirow{2}{*}{ Variable } & \multirow{2}{*}{$\beta$} & \multirow{2}{*}{$\mathrm{t}$} & \multirow{2}{*}{ SE } & \multirow{2}{*}{$\mathrm{p}$} & \multicolumn{5}{|c|}{ Model statistics } \\
\hline & & & & & $\mathrm{df}$ & $\mathrm{F}$ & $\mathrm{p}$ & $\mathrm{R}^{2}$ & $\mathrm{~N}$ \\
\hline HAM-D & & & & & 8,155 & 5.071 & 0.000 & 0.207 & 164 \\
\hline RSES & -0.368 & -4.636 & 0.095 & 0.000 & & & & & \\
\hline BIS & 0.132 & 1.669 & 0.082 & 0.097 & & & & & \\
\hline ACTH & 0.008 & 0.100 & 0.041 & 0.920 & & & & & \\
\hline AVP & -0.009 & -0.122 & 0.170 & 0.903 & & & & & \\
\hline $\mathrm{ACE}$ & 0.113 & 1.568 & 0.032 & 0.119 & & & & & \\
\hline Cortisol & 0.012 & 0.143 & 0.091 & 0.887 & & & & & \\
\hline HAM-A & & & & & 8,155 & 3.221 & 0.002 & 0.143 & 164 \\
\hline RSES & -0.161 & -1.957 & 0.100 & 0.052 & & & & & \\
\hline BIS & 0.251 & 3.050 & 0.087 & 0.003 & & & & & \\
\hline ACTH & 0.033 & 0.376 & 0.044 & 0.708 & & & & & \\
\hline AVP & -0.035 & -0.464 & 0.180 & 0.644 & & & & & \\
\hline $\mathrm{ACE}$ & 0.089 & 1.182 & 0.034 & 0.239 & & & & & \\
\hline Cortisol & -0.049 & -0.558 & 0.096 & 0.578 & & & & & \\
\hline
\end{tabular}

HAM-D: Hamilton Rating Scale for Depression, HAM-A: Hamilton Anxiety Rating Scale, BIS: Body Image Scale, RSES: Rosenberg Self Esteem Scale, ACTH: adrenocorticotropic hormone, AVP: arginine-vasopressin, ACE: angio 


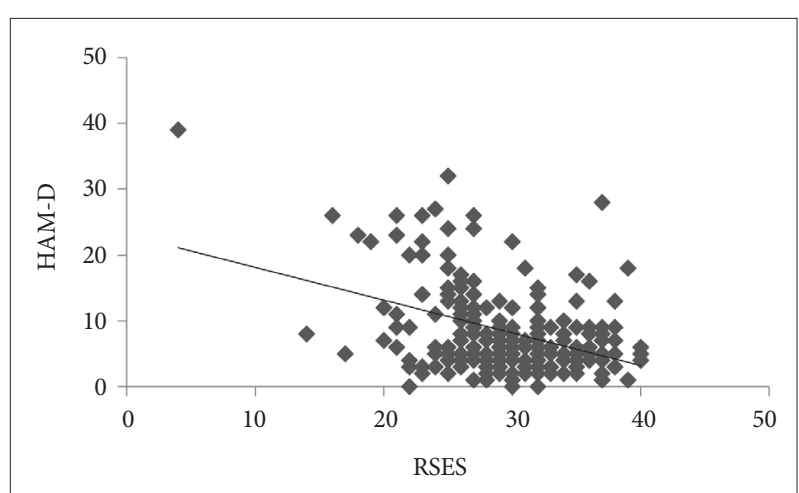

Figure 1. Association between HAM-D score and RSES. Figures reflect unadjusted data values. HAM-D: Hamilton Rating Scale for Depression, RSES: Rosenberg Self Esteem Scale.

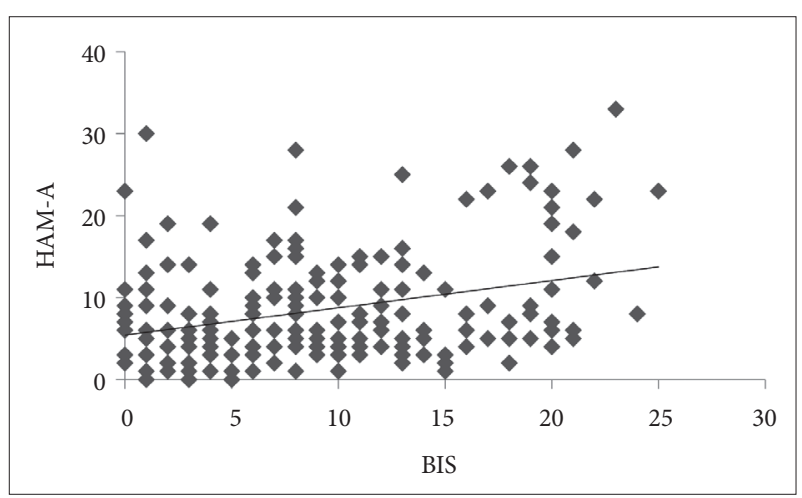

Figure 2. Association between HAM-A score and BIS. Figures reflect unadjusted data values. HAM-A: Hamilton Anxiety Rating Scale, BIS: Body Image Scale.

of surgery. Prior studies have reported that depression and anxiety symptoms that result from breast cancer diagnosis decrease to levels similar to those observed in the general population by the 1-year follow-up. However, at the 5 -year followup, patients tend to be more affected by individual factors (e.g., young age, past psychological history, and lack of social support) than by disease or treatment-related factors (e.g., number of infiltrated axillary lymph nodes, size of tumor, biopsy results, and type of axillary treatment). ${ }^{6,28}$ As demonstrated in the present study, factors that exist prior to the diagnosis of breast cancer, such as social relations, psychiatric history, and age, are more highly associated with the onset of depression and anxiety than disease-specific factors. ${ }^{6}$ Furthermore, while several studies have reported that the stage of cancer and tumor grade are not particularly associated with the severity of psychosocial symptoms such as depression and quality of life, some studies ${ }^{29,30}$ have reported that patients experience high anxiety in stage I, which subsides in stage II but increases again in stages III and IV. The popular theory posits that patients have high anxiety in stage I, as it is their first encounter with cancer, but as the cancer progresses to stage II, they adapt to the disease and their anxiety may decline. Stage
III and IV patients, on the other hand, may have higher levels depression and anxiety due to reduced quality of life caused by other treatments, such as chemotherapy and radiotherapy, as well as prolonged treatment. However, these studies ${ }^{29,30}$ also found that the effect of cancer stage on depression and anxiety is marginal or not impressive, indicating a low clinical significance of the effects of cancer stage.

In the present study, we set the cut-off scores for HAM-D and HAM-A at those corresponding to the presence of at least mild symptoms. Although many patients exhibited mild or more severe symptoms, the proportions of patients exhibiting moderate or severe depression and anxiety were 10.6\% and $15.6 \%$, respectively, which were lower than those reported by prior studies. ${ }^{8-10}$ These differences in the prevalence of symptoms may be due to differences in time of symptom assessment, as the present study assessed levels of depression and anxiety within three weeks of surgery, while other studies have assessed the symptoms within one year of surgery. ${ }^{8,9}$ However, our prevalence was similar to that of another Korean study that assessed the prevalence of depression and anxiety within one month of surgery. ${ }^{31}$

Several studies have examined the association among postbreast cancer surgery depression symptoms, HPA axis function, and pro-inflammatory cytokine/immune function. . $^{13,18,32,33}$ Seok et al. ${ }^{13}$ reported that preoperative post-dexamethasone serum cortisol level is associated with depressive symptoms in patients with breast cancer, suggesting that the HPA axis may be a valuable biological marker of depression and prognosis. Furthermore, Saxton et al..$^{18}$ reported that early adjustment of lifestyle habits in patients with breast cancer normalizes HPA axis regulation, thereby reducing depressive symptoms. However, in the present study, no correlation was observed between stress markers and depression/anxiety symptoms. This may be due to the cross-sectional design of our study, as a single blood test would have been insufficient to reveal such associations. Furthermore, dexamethasone suppression or dexamethasone/CRH tests are recommended due to their higher sensitivity and predictive ability of HPA axis function than blood ACTH and cortisol levels, ${ }^{34}$ but we were unable to utilize these methods in the present study.

Some studies ${ }^{35,36}$ have reported that there is no reliable relationship between indices pertaining to the HPA axis and measurements of mood, though it remains unclear whether this represents a true lack of correlation or an issue with methodology, as some have argued that conceptualization of mood may be a confounding factor. ${ }^{37}$ Positive or negative mood can be distinguished through state and trait measures of mood, and trait measures of mood have been more highly associated with levels of cortisol than state measures. ${ }^{37,38}$ However, the present cross-sectional study only measured symptoms at a 
single time point using the HAM-D and HAM-A, which may have been inadequate for use as trait measures of mood. Hence, in addition to biological markers, a more accurate conceptualization and measurement of mood are required to identify the variables influencing the relationship between mood and HPA axis function.

The present study possesses a few limitations. As we utilized a cross-sectional design, preoperative psychological assessments were not conducted, and we were unable to compare the patients' preoperative and postoperative psychological states. Thus, we could not identify whether the depression and anxiety symptoms that were observed after breast cancer surgery were improved or aggravated by the surgery. Furthermore, we did not track changes in the levels of stress markers. Regardless of the fact that the majority of patients with breast cancer are females, males also experience breast cancer. Considering that men with breast cancer probably have significant mental distress due to the perception that breast cancer is a 'woman's disease', it would be interesting to evaluate psychological symptoms in these patients as well. It is also important and potential limitation of the present study.

The results of our study indicate that about $40-50 \%$ of patients with breast cancer exhibit postoperative depression and anxiety, which are related to low levels of self-esteem and distorted body image. Hence, appropriate management of depression and anxiety during the treatment of breast cancer may be conducive to disease treatment and promote increased quality of life.

\section{REFERENCES}

1. Watson M, Greer S, Rowden L, Gorman C, Robertson B, Bliss JM, et al. Relationships between emotional control, adjustment to cancer and depression and anxiety in breast cancer patients. Psychol Med 1991; 21:51-57.

2. DeSantis C, Ma J, Bryan L, Jemal A. Breast cancer statistics, 2013. CA Cancer J Clin 2014;64:52-62.

3. Mols F, Vingerhoets AJ, Coebergh JW, van de Poll-Franse LV. Quality of life among long-term breast cancer survivors: a systematic review. Eur J Cancer 2005;41:2613-2619.

4. Andritsch E, Dietmaier G, Hofmann G, Zloklikovits S, Samonigg H. Global quality of life and its potential predictors in breast cancer patients: an exploratory study. Support Care Cancer 2007;15:21-30.

5. Shapiro SL, Lopez AM, Schwartz GE, Bootzin R, Figueredo AJ, Braden CJ, et al. Quality of life and breast cancer: relationship to psychosocial variables. J Clin Psychol 2001;57:501-519.

6. Christensen S, Zachariae R, Jensen AB, Vaeth M, Moller S, Ravnsbaek J, et al. Prevalence and risk of depressive symptoms 3-4 months postsurgery in a nationwide cohort study of Danish women treated for early stage breast-cancer. Breast Cancer Res Treat 2009;113:339-355.

7. Fann JR, Thomas-Rich AM, Katon WJ, Cowley D, Pepping M, McGregor BA, et al. Major depression after breast cancer: a review of epidemiology and treatment. Gen Hosp Psychiatry 2008;30:112-126.

8. Fallowfield LJ, Hall A, Maguire GP, Baum M. Psychological outcomes of different treatment policies in women with early breast cancer outside a clinical trial. BMJ 1990;301:575-580.
9. Goldberg JA, Scott RN, Davidson PM, Murray GD, Stallard S, George WD, et al. Psychological morbidity in the first year after breast surgery. Eur J Surg Oncol 1992;18:327-331.

10. Hall A, A'Hern R, Fallowfield L. Are we using appropriate self-report questionnaires for detecting anxiety and depression in women with early breast cancer? Eur J Cancer 1999;35:79-85.

11. Falk Dahl CA, Reinertsen KV, Nesvold IL, Fossa SD, Dahl AA. A study of body image in long-term breast cancer survivors. Cancer 2010; 116:3549-3557.

12. Fingeret MC, Nipomnick SW, Crosby MA, Reece GP. Developing a theoretical framework to illustrate associations among patient satisfaction, body image and quality of life for women undergoing breast reconstruction. Cancer Treat Rev 2013;39:673-681.

13. Seok JH, Kim LS, Hong N, Hong HJ, Kim SJ, Kang HJ, et al. Psychologi$\mathrm{cal}$ and neuroendocrinological characteristics associated with depressive symptoms in breast cancer patients at the initial cancer diagnosis. Gen Hosp Psychiatry 2010;32:503-508.

14. Ribeiro SC, Tandon R, Grunhaus L, Greden JF. The DST as a predictor of outcome in depression: a meta-analysis. Am J Psychiatry 1993; 150:1618-1629.

15. Leonard BE. The HPA and immune axes in stress: the involvement of the serotonergic system. Eur Psychiatry 2005;20(Suppl 3):S302-S306.

16. Ma XM, Lightman SL. The arginine vasopressin and corticotrophinreleasing hormone gene transcription responses to varied frequencies of repeated stress in rats. J Physiol 1998;510(Pt 2):605-614.

17. Baghai TC, Binder EB, Schule C, Salyakina D, Eser D, Lucae S, et al. Polymorphisms in the angiotensin-converting enzyme gene are associated with unipolar depression, ACE activity and hypercortisolism. Mol Psychiatry 2006;11:1003-1015.

18. Saxton JM, Scott EJ, Daley AJ, Woodroofe M, Mutrie N, Crank H, et al. Effects of an exercise and hypocaloric healthy eating intervention on indices of psychological health status, hypothalamic-pituitary-adrenal axis regulation and immune function after early-stage breast cancer: a randomised controlled trial. Breast Cancer Res 2014;16:R39.

19. Hamilton M. A rating scale for depression. J Neurol Neurosurg Psychiatry 1960;23:56-62.

20. Riedel M, Moller HJ, Obermeier M, Schennach-Wolff R, Bauer M, Adli $\mathrm{M}$, et al. Response and remission criteria in major depression--a validation of current practice. J Psychiatr Res 2010;44:1063-1068.

21. Hamilton M. The assessment of anxiety states by rating. Br J Med Psychol 1959;32:50-55.

22. Matza LS, Morlock R, Sexton C, Malley K, Feltner D. Identifying HAMA cutoffs for mild, moderate, and severe generalized anxiety disorder. Int J Methods Psychiatr Res 2010;19:223-232.

23. Hopwood P, Fletcher I, Lee A, Al Ghazal S. A body image scale for use with cancer patients. Eur J Cancer 2001;37:189-197.

24. Rosenberg M. Society and the Adolescent Self-Image. Princeton: Princeton University Press; 1965.

25. Ando N, Iwamitsu Y, Kuranami M, Okazaki S, Nakatani Y, Yamamoto $\mathrm{K}$, et al. Predictors of psychological distress after diagnosis in breast cancer patients and patients with benign breast problems. Psychosomatics 2011;52:56-64.

26. Fobair P, Stewart SL, Chang S, D’Onofrio C, Banks PJ, Bloom JR. Body image and sexual problems in young women with breast cancer. Psychooncology 2006;15:579-594.

27. Lam WW, Li WW, Bonanno GA, Mancini AD, Chan M, Or A, et al. Trajectories of body image and sexuality during the first year following diagnosis of breast cancer and their relationship to 6 years psychosocial outcomes. Breast Cancer Res Treat 2012;131:957-967.

28. Burgess C, Cornelius V, Love S, Graham J, Richards M, Ramirez A. Depression and anxiety in women with early breast cancer: five year observational cohort study. BMJ 2005;330:702.

29. Osborne RH, Elsworth GR, Hopper JL. Age-specific norms and determinants of anxiety and depression in 731 women with breast cancer recruited through a population-based cancer registry. Eur J Cancer 2003; 
39:755-762.

30. Hinz A, Krauss O, Hauss JP, Hockel M, Kortmann RD, Stolzenburg JU, et al. Anxiety and depression in cancer patients compared with the general population. Eur J Cancer Care (Engl) 2010;19:522-529.

31. Choi B PJ, Choe B, Han S, Kim S. Factors influencing anxiety and depression in breast cancer patients treated with surgery. J Korean Soc Biol Ther Psychiatry 2011;17:87-95.

32. Soygur H, Palaoglu O, Akarsu ES, Cankurtaran ES, Ozalp E, Turhan L, et al. Interleukin-6 levels and HPA axis activation in breast cancer patients with major depressive disorder. Prog Neuropsychopharmacol Biol Psychiatry 2007;31:1242-1247.

33. Bouchard LC, Antoni MH, Blomberg BB, Stagl JM, Gudenkauf LM, Jutagir DR, et al. Postsurgical Depressive Symptoms and Proinflammatory Cytokine Elevations in Women Undergoing Primary Treatment for Breast Cancer. Psychosom Med 2016;78:26-37.
34. Heuser I, Yassouridis A, Holsboer F. The combined dexamethasone/ $\mathrm{CRH}$ test: a refined laboratory test for psychiatric disorders. J Psychiatr Res 1994;28:341-356.

35. Edwards S, Hucklebridge F, Clow A, Evans P. Components of the diurnal cortisol cycle in relation to upper respiratory symptoms and perceived stress. Psychosom Med 2003;65:320-327.

36. Porter LS, Mishel M, Neelon V, Belyea M, Pisano E, Soo MS. Cortisol levels and responses to mammography screening in breast cancer survivors: a pilot study. Psychosom Med 2003;65:842-848.

37. Polk DE, Cohen S, Doyle WJ, Skoner DP, Kirschbaum C. State and trait affect as predictors of salivary cortisol in healthy adults. Psychoneuroendocrinology 2005;30:261-272.

38. van Eck M, Berkhof H, Nicolson N, Sulon J. The effects of perceived stress, traits, mood states, and stressful daily events on salivary cortisol. Psychosom Med 1996;58:447-458. 